Document downloaded from:

http://hdl.handle.net/10251/85104

This paper must be cited as:

Sall, T.; Mollar García, MA.; Marí, B. (2016). Substrate Influences on the Properties of SnS Thin Films Deposited by Chemical Spray Pyrolysis Technique for Photovoltaic Applications. Journal of Materials Science. 51(16):7607-7613. doi:10.1007/s10853-016-0039-9.

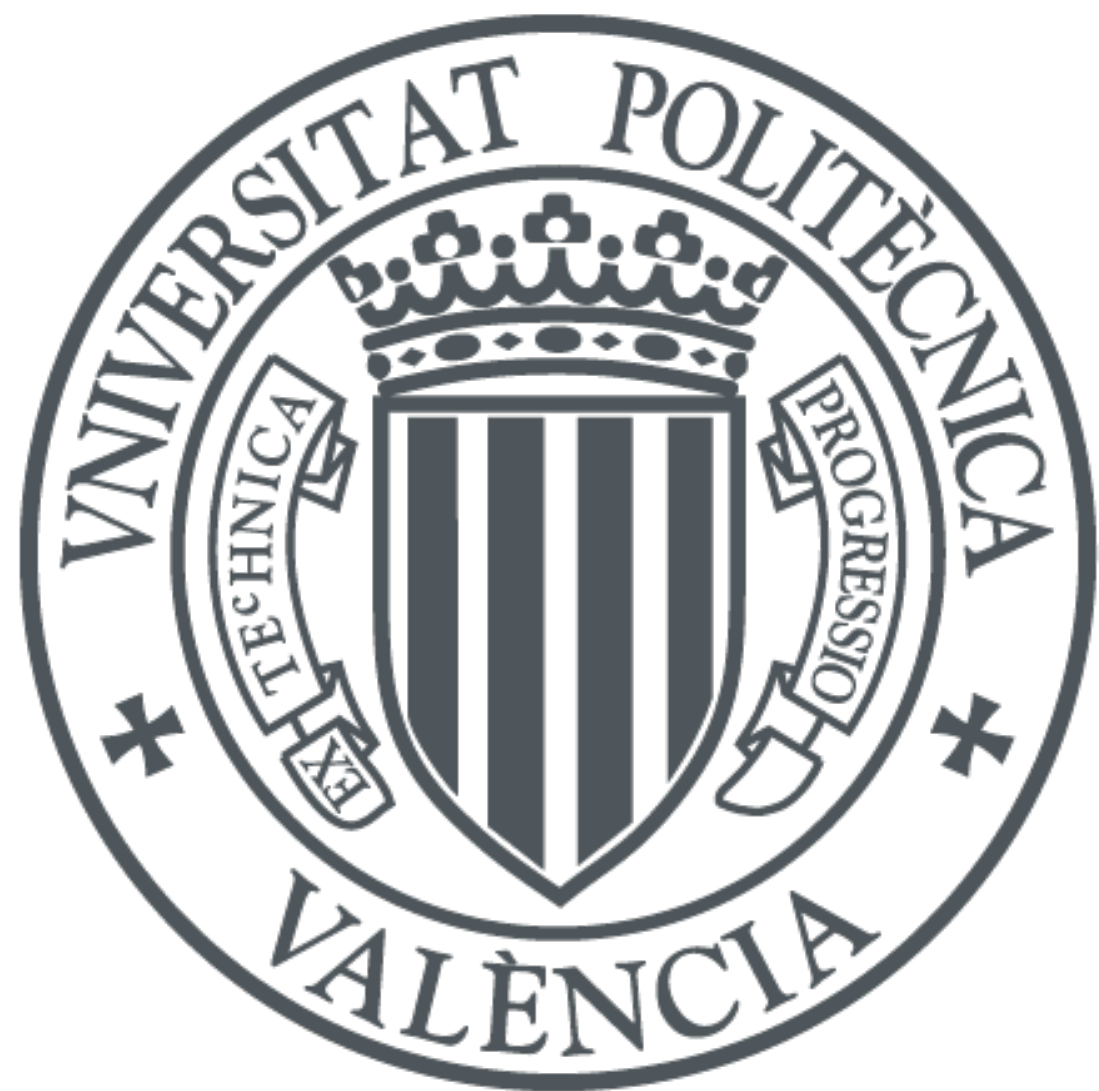

The final publication is available at

http://dx.doi.org/10.1007/s10853-016-0039-9

Copyright Springer Verlag (Germany)

Additional Information

The final publication is available at Springer via http://dx.doi.org/10.1007/s10853-016-00399. 


\title{
Substrate Influences on the Properties of SnS Thin Films Deposited by Chemical Spray Pyrolysis Technique for Photovoltaic Applications
}

\author{
Thierno Sall, Miguel Mollar, "Bernabé Marí \\ Institut de Disseny i Fabricació, Universitat Politècnica de València, Camí de Vera s/n 46022- \\ Valencia, Spain \\ *Corresponding autor: bmari@fis.upv.es
}

Keywords: SnS, Thin Films, Substrate, Chemical Spray Pyrolysis, XRD, Raman Spectroscopy, AFM, SEM.

\begin{abstract}
The present paper reports on Tin Monosulphide $(\mathrm{SnS})$ thin films elaborated by the Chemical Spray Pyrolysis (CSP) technique onto various substrates as simple glass, ITO- and Mo-coated glass in order to study the influence of substrates on the physical and chemical properties of SnS thin films. The structural analysis revealed that all films are crystallized in orthorhombic structure with (111) as the sole preferential direction without secondary phases. In addition, films prepared onto pure glass exhibits better crystallization compared to films deposited onto coated-glass substrates. Raman spectroscopy analysis confirms the results obtained from XRD with modes corresponding well to SnS single crystal orthorhombic ones (47, 65, 94, 160, 186, and $219 \mathrm{~cm}^{-1}$ ) without any additional parasite secondary phase like $\mathrm{Sn}_{2} \mathrm{~S}_{3}$ or $\mathrm{SnS}_{2}$. FESEM revealed that all films have cornflake like particles surface morphology and EDS analysis showed the presence of sulphur and tin with nearly stoichiometric ratio in films deposited onto pure glass. High surface roughness and large grains have been observed in film deposited onto glass. From optical spectroscopy it is inferred that band gap energy of SnS/glass and SnS/ITO were $1.64 \mathrm{eV}$ and $1.82 \mathrm{eV}$, respectively.
\end{abstract}




\section{Introduction}

IV-IV group compound semiconductors attracted great attention of many researchers due to their surpassed applications in the production of infrared rays and detection. IV-IV semiconductors have also play very significant role in the synthesizing of photovoltaic devices because of their suitable characteristics like high optical transmittance or absorbance, energy band gap and electrical properties [1]. SnS is one of IV-IV semiconductors and was first reported by a german mineragist Herzenberg in 1932 [2]. It has an orthorhombic structure and in the structure, six $\mathrm{S}$ atoms surround one $\mathrm{Sn}$ atom in which three $\mathrm{S}$ atoms reside at a distance of $2.68 \AA$ with interatomic angles of $88^{\circ} 10^{\prime}, 88^{\circ} 10^{\prime}$, and $95^{\circ} 8^{\prime}$; and other three $\mathrm{S}$ atoms at a distance of $3.38 \AA$ with interaction angles of $118^{\circ}, 118^{\circ}$, and $75^{\circ}$ [3]. It has direct band gap near to $1.3 \mathrm{eV} \mathrm{[4],} \mathrm{which} \mathrm{is} \mathrm{close} \mathrm{to} \mathrm{optimal} \mathrm{band} \mathrm{gap} \mathrm{(1.5} \mathrm{eV)} \mathrm{of} \mathrm{solar} \mathrm{cells} \mathrm{and} \mathrm{has}$ high absorption coefficient $\left(\alpha>10^{4} \mathrm{~cm}^{-1}\right)$ [5]. The constituent elements are inexpensive, nontoxic and abundant on Earth compared to cadmium sulphide. H. Ullah and B. Marí were studied the numerical analysis of SnS polycrystalline and found after optimization of different parameters and layer thickness a maximum efficiency of $10.6 \%$ [6].

Several techniques were used to prepare $\mathrm{SnS}$ thin films like Chemical Bath Deposition (CBD) [7], Atomic Layer Deposition (ALD) [8], Chemical Spray Pyrolysis Deposition (CSPD) [9] etc. One used Chemical Spray Pyrolysis in this work because it is simple and low cost technique and it is also suitable for industrial scale production.

In this work we prepared $\mathrm{SnS}$ thin films onto various substrates (bare glass, ITO-coated glass and Mo-coated glass) in order to evaluate the influences of the substrates nature on the chemical and physical properties of sprayed SnS thin films.

\section{Experimental}

\subsection{Films preparation}

For the preparation of $\mathrm{SnS}$ thin films by Chemical Spray Pyrolysis we used aqueous solution containing Tin (II) chloride dihydrate $\left(\mathrm{SnCl}_{2} \cdot 2 \mathrm{H}_{2} \mathrm{O}\right)$, thiourea $\left(\mathrm{CS}\left(\mathrm{NH}_{2}\right)_{2}\right)$ and alcohol (10\% in volume) to reduce the surface tension of water. The utilization of Sn (II) rather Sn (IV) was to mitigate possible contamination by $\mathrm{Sn}_{2} \mathrm{~S}_{3}$ and $\mathrm{SnS}_{2}$ phases [10]. The concentration of tin chloride was fixed at $0.104 \mathrm{M}$ and the $[\mathrm{S}] /[\mathrm{Sn}]$ ratio was 1 . The substrate temperature was kept to $350{ }^{\circ} \mathrm{C}$. A volume of $5 \mathrm{~mL}$ was spayed at a rate of $1.5 \mathrm{~mL} / \mathrm{min}$. The 
air-compressed pressure was 0.7 bar and the distance between the substrate and the nozzle 25 $\mathrm{cm}$.

All substrates were washed in ultrasonic bath of acetone for 15 minutes, rinsed with distilled water following by washed in a bath ethanol for 15 minutes and rinsed with distilled water before dried and used for spray deposition.

\subsection{Films Characterization}

Structural properties were characterized by means of X-ray diffraction (XRD) measurement with a Rigaku Ultima IV diffractometer in Bragg-Bentano $(\Theta-2 \Theta)$ configuration and using CuK $\alpha$ radiation (1.5418 ̊̊). Phonons vibrations properties were also characterized by Raman scattering measurements performed with LabRAM HR UV spectrometer coupled to a Peltiercooled CCD camera with a spectral resolution of $3 \mathrm{~cm}^{-1}$ and using a $632.81 \mathrm{~nm}$ laser excitation line. Surface morphology views were characterized using a Field Emission Scanning Electron Microscope (FE-SEM) model Zeiss ULTRA 55 equipped with In-Lens and secondary electrons detectors. Atomic Force Microscopy (AFM) analysis was carried out using a Bruker Multimode 8 AFM Nanoscope V controller. Optical properties were monitored by transmittance using a Deuterium-Halogen lamp (DT-MINI-2-GS Micro Park) in association with $500 \mathrm{~mm}$ Yvon-Jobin HR460 spectrophotometer using a back-thinned Si-CCD detector (Hamamatsu) optimized for the UV-VIS-Infrared range.

\section{Results and Discussion}

\subsection{X-Ray Diffraction (XRD) analysis}

X-ray diffraction is an effective method to investigate crystalline properties of a synthesized material. X-ray diffraction spectra of $\mathrm{SnS}$ thin film deposited by chemical spray pyrolysis onto pure glass, ITO and Mo-coated glass substrates shown in Fig. 1 revealed a unique XRD peak located at $31.78^{\circ}$, which correspond to the preferential crystallographic direction oriented along (111) planes for all samples without any additional parasite phase like $\mathrm{SnS}_{2}$, $\mathrm{Sn}_{2} \mathrm{~S}_{3}$ or $\mathrm{SnO}_{2}$. Thin films deposited on glass substrates showed only one shape peak whereas for films deposited onto ITO and Mo-coated glass other peaks corresponding to ITO and Mo are visible. The observed diffraction peak for $\mathrm{SnS}$ matches well with $\mathrm{SnS}$ Herzenbergite orthorhombic structure phase and is in good agreement with the standard data (Ref. JCPDS card, PDF\#39-0354). The intensity of (111) diffraction peak is higher in films deposited onto bare glass substrates than in films deposited onto ITO or Mo-coated glass substrates indicating that films deposited on glass have minimum potential energy of the nuclei on the surface of the glass substrate leading to the enhanced crystallite size [5]. 


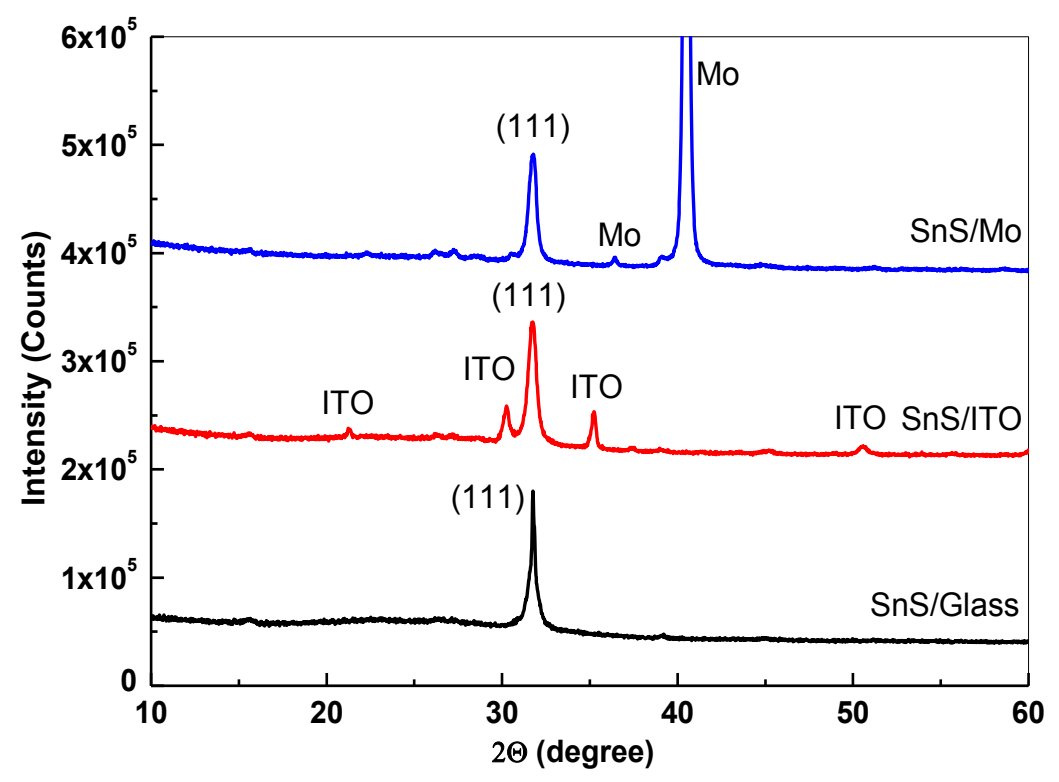

Fig. 1 XRD spectra of SnS thin films deposited onto various substrates

The variation of crystallite size with the substrate nature was also evaluated using Scherrer's formula from (111) diffraction line [11].

$$
D=K \lambda / \beta \cos \Theta
$$

The microstrain ( $\varepsilon$ ) can also be calculated using equation (2) [12].

$$
\varepsilon=\beta \cos \Theta / 4
$$

The dislocation density $(\delta)$ is calculated using the Williamson and Smallman's formula [13].

$$
\delta=1 / D^{2}
$$

where $\beta$ is the Full Width at Half Maximum (FWHM), $\lambda$ wavelength of X-ray whose value is $1.5418 \AA(\mathrm{CuK} \alpha), \mathrm{K}$ the Scherrer constant which generally depends on the crystallite shape and is close to 1 ( $\mathrm{K}=0.9$ was used) and $\Theta$ is the Bragg angle at the center of the peak. The crystallite size, $\mathrm{D}$, obtained from this equation corresponds to the mean minimum dimension of a coherent diffraction domain.

Table 1 displays the crystallite size (D), microstrain $(\varepsilon)$ and dislocation density $(\delta)$ for $\mathrm{SnS}$ thin films deposited on to different substrates. It is worth to notice that films prepared onto glass have greater crystallite size compared to others because its crystallinity is better than films deposited onto ITO and Mo-coated glass.

The microstrain and dislocation variation was correlated to the grain size with the substrate nature change. The smaller value of microstrain and dislocation density of films deposited onto simple glass substrates indicated densely packed structure with minimum defects, good crystallinity and high-quality of SnS/Glass film compared to the rest. 
Table 1 Grains size of $\mathrm{SnS}$ deposited at various substrate temperatures

\begin{tabular}{|c|c|c|c|}
\hline Sample & $\mathrm{D}(\AA)$ & $\varepsilon\left(10^{-3}\right)$ & $\delta\left(10^{7}\right.$ lines.m $\left.^{-2}\right)$ \\
\hline SnS/Glass & 459 & 0.75 & 2.17 \\
\hline SnS/ITO & 160 & 2.16 & 6.25 \\
\hline SnS/Mo & 183 & 1.89 & 4.46 \\
\hline
\end{tabular}

\subsection{Raman spectroscopy analysis}

Raman analysis was also used because it is a highly sensitive tool to analyze the structural and compositional changes of the thin films [14].

The orthorhombic structure has 24 vibrational modes represented at the centre of Brillouin zone by the following irreductible representations below:

$$
\Gamma=4 A g+2 B 1 g+4 B 2 g+2 B 3 g+2 A u+4 B 1 u+2 B 2 u+4 B 3 u
$$

For $\mathrm{SnS} 21$ optical phonons modes are detected of which 12 are Raman active modes (4Ag, 2B1g, 4B2g and 2B3g) [15].

Figure 2 shows the Raman spectra of SnS/Glass, SnS/ITO and SnS/Mo films analyzed within the range $30-300 \mathrm{~cm}^{-1}$. It was observed that Raman spectra for all samples are similar with only small variations in the intensity of the Raman signal. The modes detected in our study are located at 47,65, 94, 160, 186 and $219 \mathrm{~cm}^{-1}$, all corresponding to $\mathrm{SnS}$ single crystal modes [16] without any contamination of secondary phases. Modes located at 94, 186 and $219 \mathrm{~cm}^{-1}$ are assigned to $\mathrm{Ag}$ modes while $47,163 \mathrm{~cm}^{-1}$ are attributed to $\mathrm{B} 3 \mathrm{~g}$ mode and 65 is attributed to B2g or B1g modes. The modes obtained were the same that these observed by $\mathrm{H}$. R. Chandrasekhar et al. [16]. The modes obtained confirm the results given by the XRD analysis. 


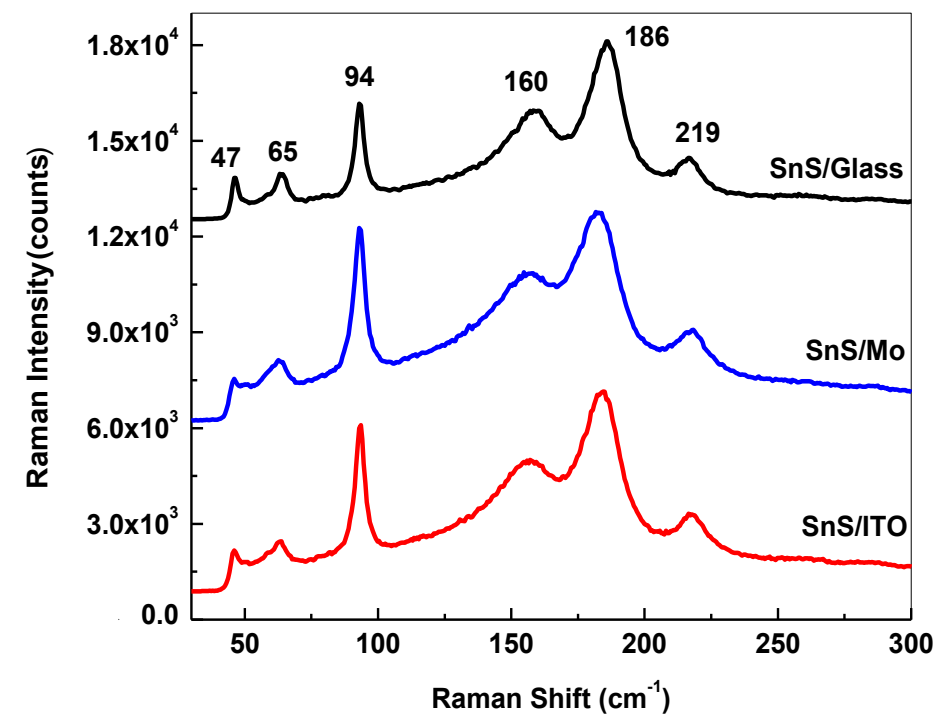

Fig. 2 Raman spectra of SnS thin films deposited onto pure glass, ITO and Mo-coated glass substrate at $350{ }^{\circ} \mathrm{C}$.

\subsection{Scanning Electron Microscopy (SEM) analysis and EDS measurements}

Field Emission Scanning Electron Microscope (FESEM) was used to analyze the surface morphology of $\mathrm{SnS}$ thin films deposited onto various substrates.

Figure 3 shows that all films are formed by cornflake like particles, homogeneous, with uniform surface and good adhesion to substrates. Substrates are well covered and no pinholes are observed. Films deposited onto ITO and Mo-coated glass are denser and more compact than those deposited on bare glass. N. Revathi et al. found the same result using PVD technique to grow $\mathrm{SnS}$ onto different surfaces [17].
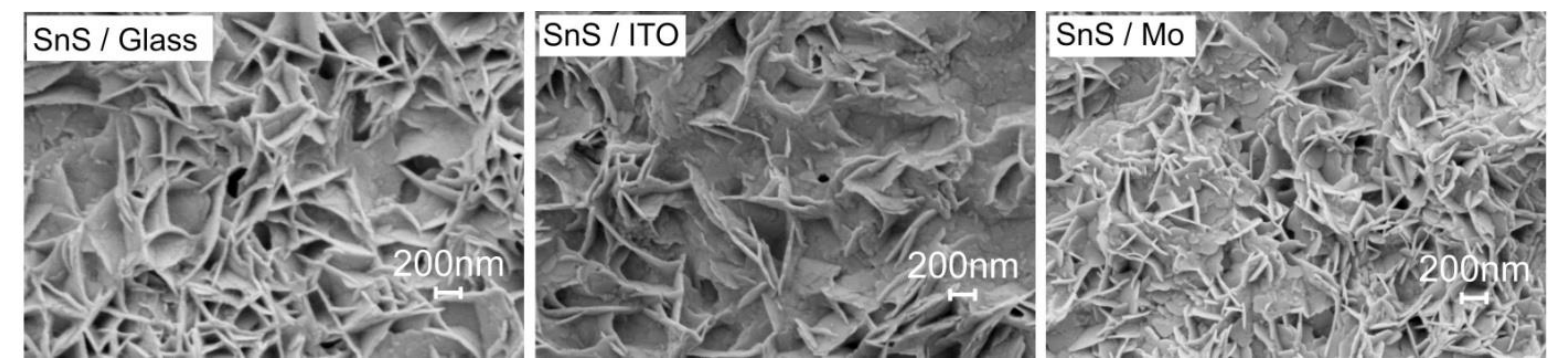

Fig. 3 FESEM images of $\mathrm{SnS}$ thin films deposited on different substrates.

The composition of sprayed SnS thin films was estimated by Energy Dispersive X-Ray Spectroscopy (EDS). The EDS spectra revealed the presence of sulphur and tin in all films. Films deposited onto bare glass substrates were nearly stoichiometric, whereas films deposited onto ITO had a little excess of tin coming certainly from the ITO substrate. An excess of tin was also detected in films deposited onto Mo-coated glass substrates. The atomic 
percentages of these elements are shown in Table 2. Non-stoichiometric SnS can be due to either $\mathrm{Sn}^{2+}$ vacancies or excess tin atoms contains deep acceptor states with activation energy in large range between 0.22 and $0.45 \mathrm{eV}$ depending on the deposition technique [18-19-20, 21]. The deficiency of sulphur can be attributed to the evaporation of sulphur due to the temperature of the substrate during the spray process.

Table 2 Composition of $\mathrm{SnS}$ thin films deposited at various substrate temperatures as obtained from EDS analysis.

\begin{tabular}{|l|c|c|c|}
\hline \multicolumn{1}{|c|}{ Samples } & Sn $(\%)$ & S (\%) & Sn/S \\
\hline SnS/Glass & 50.5 & 49.5 & 1.02 \\
\hline SnS/ITO & 53.8 & 46.2 & 1.15 \\
\hline SnS/Mo & 60.0 & 40.0 & 1.50 \\
\hline
\end{tabular}

\subsection{Atomic Force Microscopy (AFM) analysis}

Figure 3 shows AFM images of films prepared by chemical spray pyrolysis technique onto pure glass, ITO and Mo-coated glass. The scan area surface was $7 \mu \mathrm{m} \times 7 \mu \mathrm{m}$. The images agreed well with the FESEM images and confirmed that films are formed by like cornflake particles. This morphology has been observed in all samples with more compact film on Mocoated substrate.

The grain size and the RMS (Root-Mean-Square) surface roughness values are reported in Table 3. The films deposited onto glass had large grains and high surface roughness. It can be explained by the fact that the improvement of crystallinity due to the coalescence of small grains to form large ones increases grain boundaries and then increases the roughness.

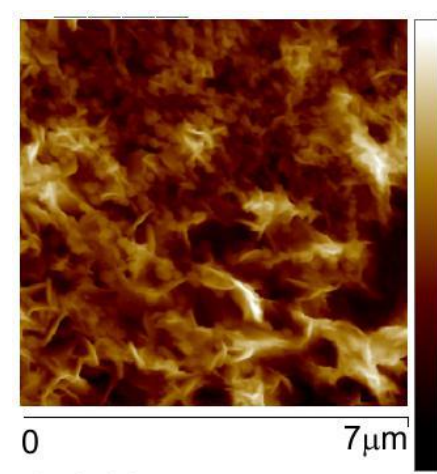

SnS / Glass

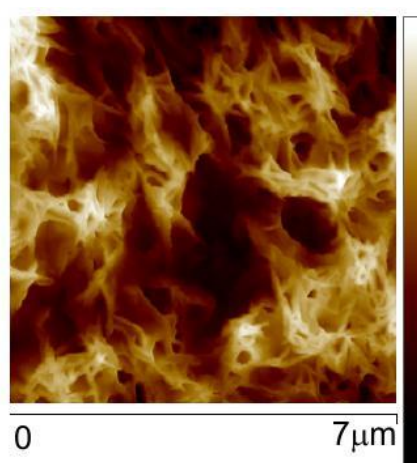

SnS / ITO
Z: $600 \mathrm{~nm}$

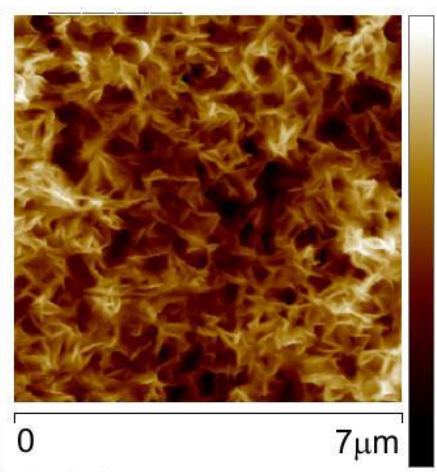

Z: $600 \mathrm{~nm}$

Fig. 4 AFM micrographs of samples SnS films deposited by chemical spray pyrolysis onto different substrates. 
Table 3 Roughness and grain size of $\mathrm{SnS}$ sprayed on various substrates

\begin{tabular}{|c|c|c|}
\hline Samples & Roughness $(\mathrm{nm})$ & Grain size $(\mathrm{nm})$ \\
\hline SnS/Glass & 89 & 286 \\
\hline SnS/ITO & 138 & 175 \\
\hline SnS/Mo & 77 & 234 \\
\hline
\end{tabular}

\subsection{Optical analysis}

The optical properties of SnS thin films deposited onto different substrates: simple glass, ITO and Mo-coated glass were studied by measuring the transmittance across the full UVVis-IR range wavelength of $300-1000 \mathrm{~nm}$. We noted a transmittance of $24 \%$ and $29 \%$ for films deposited onto pure glass and ITO respectively. The low transmittance in the visible region shows clearly that $\mathrm{SnS}$ thin film is an absorber layer.

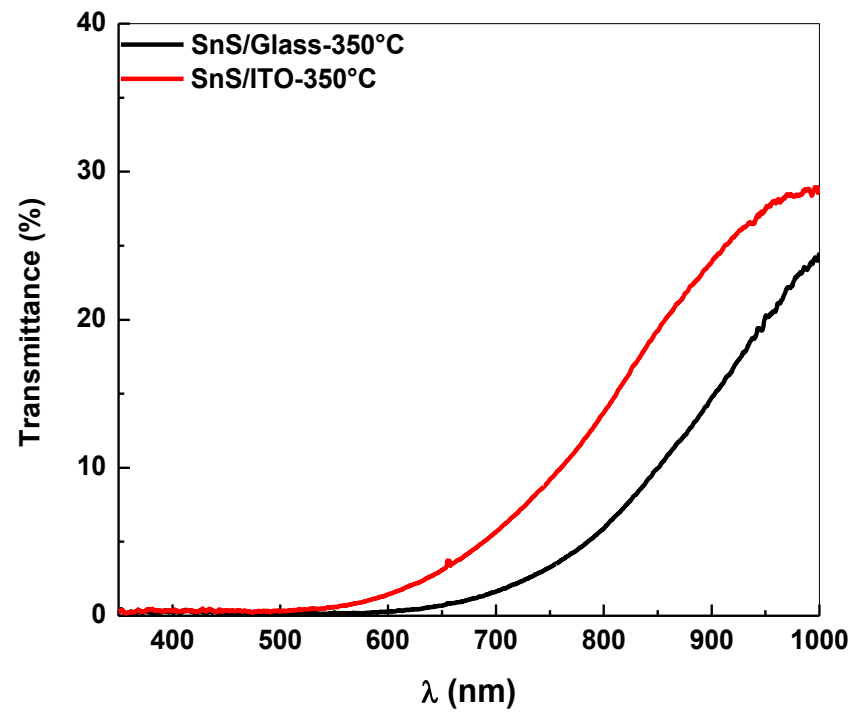

Fig. 4 Transmittance spectra of SnS thin films onto different substrates.

The band gap energy can be obtained from strapolating the straight line of $(\alpha h v)^{2}$ vs hv plot where $\alpha$ is the absorption coefficient for a direct-transition semiconductor material, $h$ the Planck constant and $v$ the frequency of the incident photon. The Eg values were found to be $1.64 \mathrm{eV}$ and $1.82 \mathrm{eV}$ for samples deposited onto pure glass and ITO-coated glass, respectively. These values are greater than theoretical estimation of the SnS band gap structure due certainly to the techniques used to synthesize our films. 


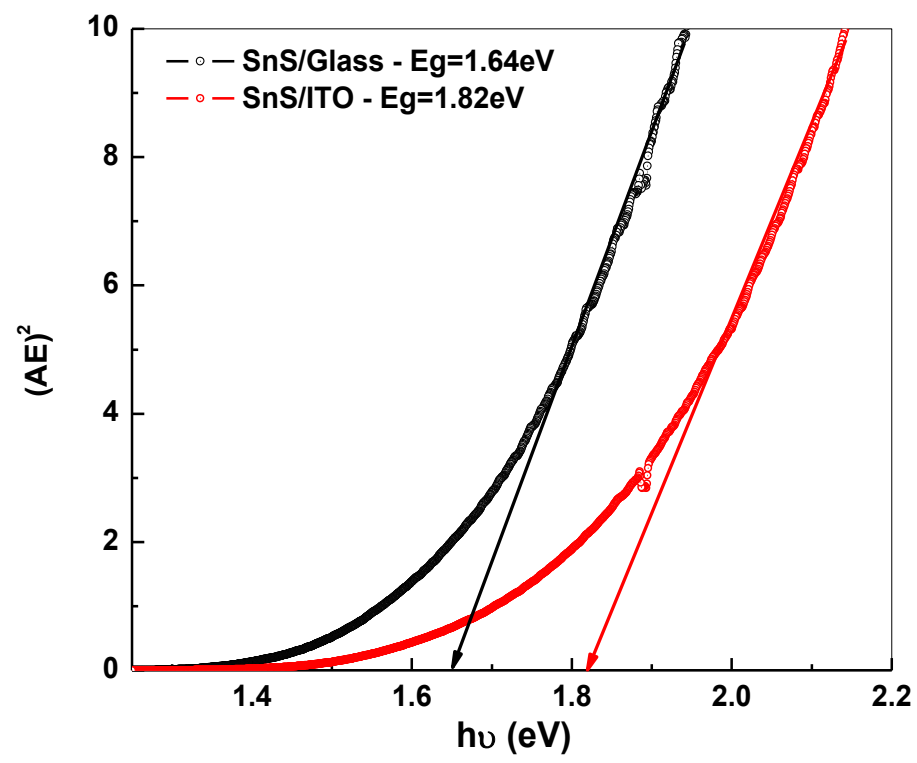

Fig. 5 Plot of $(\alpha h v)^{2}$ vs photon energy of SnS thin films sprayed onto different substrates.

\section{Conclusions}

In this work, we presented the synthesis of $\mathrm{SnS}$ thin films by Chemical Spray Pyrolysis onto various surface substrates as bare glass, ITO and Mo-coated glass. XRD study revealed that sprayed SnS films only present a diffraction peak corresponding to (111) planes. This result is independent of the substrate used and means that $\mathrm{SnS}$ films grow following the preferential direction (111). Raman spectroscopy confirmed the XRD results with modes according to $\mathrm{SnS}$ orthorhombic structure without any parasite phase for all samples. FESEM images show films are made of cornflake like particles. EDS analysis revealed the presence of sulphur and tin in all films with near stoichiometric ratio for films deposited onto glass and an excess of sulphur in films deposited on ITO and Mo coated glass. Films deposited onto glass have larger grains and high roughness. The direct band gap energy was estimated to be 1.64 and $1.82 \mathrm{eV}$ for film deposited onto simple glass and ITO-coated glass. These films have great potential for use in photovoltaic devices.

The SnS thin film prepared onto glass substrate showed better crystallinity, good morphology, band gap energy near to the ideal value and then is suitable for the solar absorber in solar cell devices using Chemical Spray Pyrolysis as experimental technique for elaboration.

\section{Acknowledgments}

This work was supported by Ministerio de Economía y Competitividad (ENE2013-46624-C4-4-R) and Generalitat valenciana (Prometeus 2014/044). 


\section{References}

1. Reddy KTR, Prathap P, Miles RW (2010) Thin films of tin sulphide for application in photovoltaic solar cells in Photovoltaics: Developments, Applications and Impact, H. Tanaka and K. Yamashita, Eds., Nova Science, New York, NY, USA:1-27.

2. Herzenberg R, Rev. Miner. 4 (1932) 33.

3. Juarez AS, Silver AT, Ortiz A (2005) Fabrication of SnS2/SnS heterojunction thin film diodes by plasma-enhanced chemical vapor deposition, Thin Solid Films 480481:452-456.

4. Mathews NR, Anaya HBM, Cortes-Jacome MA, Angeles-Chavez C, Toledo-Antonio JA (2010) Tin sulfide thin films by pulse electrodeposition: structural, morphological, and optical properties, J. Electrochem. Soc 157:H337-H341.

5. Reddy NK, Ramesh K, Ganesan R, Reddy K, Gunasekhar KR, Gopal E (2006) Synthesis and characterization of co-evaporated tin sulphide thin films, Appl. Phys. A 83:133-138.

6. Ullah H, Marí B (2014) Numerical Analysis of SnS based Polycrystalline Solar Cells, Superlattice Microst 72:148-155.

7. Avellaneda D, Nair MTS, Nair PK (2008) Polymorphic Tin Sulfide Thin Films of Zinc Blende and Orthorhombic Structures by Chemical Deposition, J. Electrochem. Soc 155:D517-D525.

8. Sinsermsuksakul P, Heo J, Noh W, Hock AS, Gordon RG (2011) Atomic Layer Deposition of Tin Monosulfide Thin Films, Adv. Energ. Mater 1:1116-1125.

9. Jeyaprakash B.G, kumar R. A, Kesavan K, Amalarani A (2010) Structural and optical characterization of spray deposited $\mathrm{SnS}$ thin film, J. Am. Sci 6:22-26.

10. Hibbert TG, Mahon MF, Molloy KC, Price LS, Parkin IP (2001) Deposition of tin sulfide thin films from novel, volatile (fluoroalkythiolato) tin (IV) precursors, J. Mater. Chem 11:469-473.

11. Senthilarasu S, Hahn YB, Lee S H (2007) Structural analysis of zinc phthalocyanine (ZnPc) thin films: X-ray diffraction study, J. Appl. Phys 102:043512.

12. Willeke G, Dasbach R, Sailer B, Bucher E (1992) Thin pyrite $\left(\mathrm{FeS}_{2}\right)$ films prepared by magnetron sputtering, Thin Solid Films 213:271-276.

13. Chowdhury A, Biswas B, Majumder M, Sanyal MK, Mallik B (2012) Studies on phase transformation and molecular orientation in nanostructured zinc phthalocyanine thin films annealed at different temperatures, Thin Solid Films 520:6695-6704. 
14. Deepa KG, Vijayakumar KP, Kartha CS (2012) Lattice vibrations of sequentially evaporated CuInSe 2 by Raman microspectrometry, Mat. Sci. Semicond. Proc 15:120124.

15. Nikolic PM, Lj Miljkovic P, Mihajlovic, Lavrencic B (1977) Splitting and coupling of lattice modes in the layer compound SnS, J. Phys. C 10:L289-L292

16. . Chandrasekhar HR, Humphreys RG, Zwick U, Cardona M (1977) Infrared and Raman of IV-IV compounds SnS and SnSe, Phys. Rev. B 15:2177-2183.

17. Revathi N, Bereznev S, Iljina J, Safonova M, Mellikov E, Volobujeva O (2013) PVD grown $\mathrm{SnS}$ thin films onto different substrate surfaces, J. Mater. Sci. Mater. Electron 24:4739-4744.

18. Wang Y, Gong H, Fan BH, Hu GX (2010) Photovoltaic Behavior of Nanocrystalline $\mathrm{SnS} / \mathrm{TiO}_{2}$, J. Phys. Chem. C 114:3256-3259.

19. Tanusevski A, Poelman D (2003) Optical and photoconductive properties of SnS thin films prepared by electron beam evaporation, Solar Energy Materials and Solar Cells, 80:297-303.

20. Sajeesh TH, Poornima N, Kartha CS, Vijayakumar KP (2010) Unveiling the defect levels in $\mathrm{SnS}$ thin films for photovoltaic applications using photoluminescence technique, Phys. Status Solidi A 207:1934-1939.

21. Sinsermsuksakul P, Heo J, Noh W, Hock AS, Gordon RG (2011) Atomic Layer Deposition of Tin Monosulfide Thin Films, Adv. Energy Mater 1:116-125. 